\title{
THE
}

\section{Retention of Student Pharmacists' Knowledge and Skills Regarding Overdose Management with Naloxone}

\author{
Anita Jackson \\ University of Rhode Island, anitajackri@uri.edu \\ P. Bratberg \\ University of Rhode Island, jefbratberg@uri.edu \\ M Monk \\ University of Rhode Island \\ J Ferrentino \\ University of Rhode Island
}

Follow this and additional works at: https://digitalcommons.uri.edu/php_facpubs

The University of Rhode Island Faculty have made this article openly available.

Please let us know how Open Access to this research benefits you.

This is a pre-publication author manuscript of the final, published article.

Terms of Use

This article is made available under the terms and conditions applicable towards Open Access

Policy Articles, as set forth in our Terms of Use.

\section{Citation/Publisher Attribution}

Anita N. Jacobson PharmD, Jeffrey P. Bratberg PharmD, Miranda Monk \& John Ferrentino (2018)

Retention of student pharmacists' knowledge and skills regarding overdose management with naloxone, Substance Abuse, 39:2, 193-198, DOI: 10.1080/08897077.2018.1439797

Available at: http://dx.doi.org/10.1080/08897077.2018.1439797

This Article is brought to you for free and open access by the Pharmacy Practice at DigitalCommons@URI. It has been accepted for inclusion in Pharmacy Practice Faculty Publications by an authorized administrator of DigitalCommons@URI. For more information, please contact digitalcommons-group@uri.edu. 
Retention of Student Pharmacists' Knowledge and Skills Regarding Overdose Management with Naloxone

\section{$\underline{\text { Abstract }}$}

Background: Overdose education and naloxone training was recently implemented into the required curriculum of the College of Pharmacy at the University of Rhode Island. The objective of this study was to compare the retention of knowledge between student pharmacists who received a didactic lecture only versus student pharmacists who received the same lecture plus a skills-based objective structured clinical examination (OSCE) with a standardized patient actor.

Methods: Students in their first-professional year (P1) of the Doctor of Pharmacy program $(n=129)$ and students in their second-professional (P2) year $(n=123)$ attended a required lecture on opioid overdose, including detailed naloxone training. P2 students were additionally required to participate in an OSCE assessment following the didactic lecture component. An anonymous, voluntary survey was offered to all students approximately 6 months later. A ChiSquare or Fisher's Exact Test was performed on the survey responses to assess any difference in the responses between the two groups.

Results: A total of 99 P1 students (76.7\%) and 116 P2 students (94.3\%) completed the survey. P1 students were found to be more knowledgeable regarding the duration of naloxone action and identification of risk factors for opioid overdose. P2 students were found to be more knowledgeable regarding non-medical ways patients may obtain opioids and the correct order of emergency response during a suspected opioid overdose...

Conclusions: P2 students did not demonstrate superior retention of information regarding naloxone and opioid use disorder on survey questions compared with P1 students. There was a trend towards P2 students feeling more confident in their ability to counsel patients for overdose prevention and reporting disagreement with the statement that "overdose prevention for people who use drugs is a waste of time and money" compared with the P1 students, but these did not reach statistical significance. Since the opioid crisis continues unabated, naloxone training using OSCE and didactic methods remain an on-going required part of the pharmacy curriculum. 


\section{Introduction}

The World Health Organization estimates that 69,000 people die each year due to drug overdose, with over 47,000 of these deaths in the United States alone. ${ }^{1}$ Of these deaths 33,000 are related to opioid overdose. Prescription opioids, including morphine, oxycodone, hydrocodone, hydromorphone and fentanyl, as well as illicit substances such as heroin and contaminated non-pharmaceutical fentanyl are responsible for these opioid related deaths, which have tripled since the year 2000., ${ }^{1,2}$

People at risk to experience an overdose are those who administer substances through nonmedical routes (i.e. injection or insufflation), utilize high doses of opioids, are co-prescribed benzodiazepines, are co-prescribed antidepressants or sedatives/hypnotics, utilize long-acting opioid formulations, use more potent opioid drugs (such as fentanyl), obtain opioid prescriptions from multiple providers and pharmacies, or have a history of mental illness, alcohol or substance abuse disorder. ${ }^{3-10}$ Opioid-related overdose risk is highest in those with decreased tolerance who relapse into use following a period of abstinence, such as time spent in detoxification programs or incarceration, particularly when quantities of drug used previously are reintroduced. ${ }^{11,12}$ Patients receiving 100 or more morphine milligram equivalents (MME) per day, compared to patients with less than $100 \mathrm{MME}$, have been shown to have an 8.9-fold increase in risk of opioid overdose. ${ }^{10}$ Many overdoses occur in the presence of one or more bystanders and with proper training and tools, especially the opioid-reversal agent naloxone, these individuals could potentially save lives by stopping an overdose from progressing. ${ }^{13}$

Naloxone is a centrally- and peripherally acting mu-, delta-, and kappa- opioid receptor antagonist which can be used to reverse opioid activity in overdose situations. Naloxone can be administered intranasally, intramuscularly, intravenously, intralingually, and subcutaneously to reverse respiratory depression and analgesia. Once administered, naloxone has an onset of 5 to 10 minutes and a duration of 30 to 90 minutes. The time to administration of a second dose in response to no effect seen with the first dose varies among routes of administration and relative time of onsets for each route. Volunteers given up to 100 times the therapeutic dose of naloxone suffered no adverse effects, which demonstrates the safety of the agent and enables the public to administer naloxone even in the absence of extensive training. ${ }^{14,15}$

Given the proper resources, such as integrated access to the prescription drug monitoring program with the dispensing software used to process and prepare prescriptions in community pharmacies, pharmacists have the opportunity to make a significant impact on community-level prescription substance use disorder prevention and treatment efforts. ${ }^{16}$ Pharmacists have daily contact with patients who are either at risk for opioid overdose themselves or know someone at risk. ${ }^{17}$ Through required clinical patient care rotations (Introductory Pharmacy Practice Experiences and Advanced Pharmacy Practice Experiences) and internships student pharmacists will encounter persons at risk for opioid overdose in community pharmacy practice and other settings. Any interaction between student pharmacists and patients is a possible opportunity to identify opioid overdose risk factors and make interventions. Therefore, student pharmacists should be trained to identify these patients at risk and be able to provide naloxone 
education and training. ${ }^{18}$

This study seeks to assess differences in the retention of knowledge (objective data) and impressions of overdose prevention efforts (subjective data) between student pharmacists who received the content delivered by a 50-minute lecture only and those who received the same lecture and completed an objective structured clinical examination (OSCE) of interactive counseling with standardized patient actors. Overdose education and naloxone training was recently implemented into the required curriculum of the College of Pharmacy at the University of Rhode Island in an effort to better prepare student pharmacists to identify intervention opportunities with at-risk patients. To better understand the most effective way to perform naloxone training and opioid overdose education this comparative study between two classes of Doctor of Pharmacy students was performed. We hypothesized that students who receive a lecture plus OSCE would score higher on the objective portion of a six month follow-up survey about overdose and naloxone education versus students who receive a lecture only. ${ }^{19}$

An OSCE format was utilized in this study due to reinforcement and retention rates demonstrated in the literature. OSCEs have been noted to increase retention of knowledge rather than just didactic lecture across multiple topics. One study of intern-level medical students found that $75 \%$ of interns were able to achieve a passing score of $60 \%$ up to 18 months after an OSCE, and the remaining $25 \%$ of interns who did not pass the original OSCE quickly re-learned skills. ${ }^{20}$ Another study with Doctor of Pharmacy students found that students working in a simulated environment displayed increased enthusiasm toward the OSCE topic and retention of developed clinical skills, as opposed to conventional written patient cases. ${ }^{21}$

\section{Methods}

First (P1) and second (P2) professional year student pharmacists at the University of Rhode Island are required to take the skills-based Integrated Pharmacy Laboratories I and III (PHC 316 and PHC 416) in the Spring semester. All 129 students in the first-professional year and 123 students in the second-professional year were eligible for study participation by attending the same lecture on overdose response including detailed naloxone training. Second-professional year students were additionally required to participate in an OSCE with a standardized patient actor following the didactic lecture component. Students were surveyed approximately 6 months after they participated in the lecture or lecture plus OSCE in order to assess retention of material related to key points of opioid use disorder, overdose identification, and naloxone administration. The study methodology and survey instrument was reviewed and deemed to be exempt by the University of Rhode Island Institutional Review Board.

The lecture portion of the training consisted of information regarding naloxone, overdose and opioid use disorder. ${ }^{22-24}$ The OSCE required students to further prepare themselves for a simulated patient interaction where they would be required to teach an at-risk patient how to identify an overdose, check for response, call 911, give rescue breaths, properly assemble and administer intranasal naloxone, and what to expect after naloxone administration. ${ }^{25}$ Preparation was highly recommended for the mock-patient scenario, which was a team-based graded 
assignment. The overall goal of the OSCE was to have the students assess the patient's need for naloxone, teach the patient the steps of responding to an opioid overdose including administration of naloxone, and evaluate the patient's ability to teach others close to him how to respond in the event of an opioid overdose. Students in teams of 5 or 6 , were responsible for screening the patient, a local paid actor, for opioid use disorder and risk of opioid overdose through a complete history, physical exam, and review of systems. ${ }^{26}$ One or two members of the group were then responsible for counseling the patient about naloxone including its indication, duration of action, side effects, and what to expect once administered. One other team member was responsible for demonstrating to the patient how to use the atomizer/intranasal naloxone kit and then asking the patient to perform naloxone administration using the teach-back method. The multi-step intranasal kit was selected over the intramuscular versions since the auto-injector is dispensed with a "talking" trainer and the multi-step intranasal kit was the only intranasal formulation widely marketed and used in New England at the time of the study. ${ }^{27-29}$ The goal of the teach-back method was to ensure patient confidence with the information provided and assess his ability to teach proper naloxone administration to his 10 -year-old daughter in the event of an overdose situation.

The follow-up survey was given as a 21 -item multiple choice questionnaire offered via SurveyMonkey ${ }^{\circledR}$ to all students who participated in the naloxone lecture or lecture plus OSCE approximately 6 months after the course content was completed. ${ }^{30,31}$ Informed consent information was included at the beginning of the online survey for all participants and participation was indicative of consent. The survey was offered in class to all 252 students, of which 129 students received lecture only and 123 students received both the lecture and OSCE. The survey took approximately 5-10 minutes to complete and students were given the opportunity to skip any questions at any time. The survey consisted of 7 fact-based (objective) and 14 opinion-based (subjective) questions regarding opioid overdose, opioid use disorder, and use of naloxone. Survey completion was completely voluntary and students could opt out of any individual question they did not wish to answer, with no incentives nor impact on course grades. The time in class could be used by those students opting not to participate in the survey for other independent activities, such as reading or reviewing class notes. Responses to these items were collected through a secure surveying website and kept on a passwordencrypted computer. All surveys were anonymous, and de-identified data was compiled which contained no unique identifiers. No link to student names or identifying information were asked in the survey, however, the timing of the survey administration indicated the class (P1 or P2).

Survey questions were developed by the researchers and were influenced by materials found on the Prescribe to Prevent website and continuing education programs. ${ }^{32} \mathrm{~A}$ Chi-Square or Fisher's Exact Test was performed on each of the questions to assess any difference in the responses between the two groups. A significance level of $\alpha=0.05$ was set a priori. This analysis was chosen due to the independent nature of comparison between the two groups of pharmacy students. 


\section{$\underline{\text { Results }}$}

Of the 252 students that received the didactic lecture covering naloxone administration and opioid overdose, a total of $215(85.3 \%)$ students participated in the survey. A total of 99 students of the P1 students (76.7\%) and 116 students of the P2 students (94.3\%) completed the survey. As a whole, the P1 class answered $96.97 \%$ to $100 \%$ of questions and P2s answered $99.14 \%$ to $100 \%$ of the questions. Table 1 shows the results of each individual objective question. The hypothesis of the study was that P2 students who experienced both the lecture and the OSCE activity would score higher on survey questions versus the P1 students who experience the same lecture alone. Four objective questions were found to have a statistically significant difference in correct responses between the P1 and P2 students $(p<0.05)$. P2 students were significantly more knowledgeable on questions relating to ways prescriptions opioids are obtained for non-medical use and the correct order of steps in an overdose response situation. P1 students were significantly more knowledgeable on questions related to the duration of action of naloxone and greatest risk factors for opioid overdose.

Student responses to subjective or opinion-based questions are shown in Table 2. Responses were gathered by asking students to rank their impression of statements into one of three categories: Agree/True, Neutral, or Disagree/False. P2 students reported higher rates of working in a community pharmacy practice setting at the time of survey administration than did the P1 students $(p<0.05)$. While there was a trend towards P2 students reporting increased confidence versus P1 students when asked to counsel patients on overdose prevention and disagreeing with the statement "overdose prevention for people who use drugs is a waste of time and money", these did not reach statistical significance.

\section{Discussion}

Patients using opioids are experiencing mortality and morbidity from opioid overdoses at epidemic rates in the United States. ${ }^{33}$ As healthcare professionals who are in direct contact with patients who may be at risk for overdose, pharmacists have a duty to combat this epidemic by identifying at-risk patients and counseling them about response to an overdose and naloxone administration. ${ }^{14}$ This study was conducted to compare retention of overdose and naloxone knowledge between first year Doctor of Pharmacy students who received a didactic lecture alone versus second year students who participated in both a didactic lecture and a hands-on OSCE experience. Our study found significant differences in the responses to individual questions regarding naloxone and opioid overdose between the two groups, however the P2 students did not perform significantly better overall on the objective questions as hypothesized.

Interdisciplinary teaching programs that include naloxone training should be designed to meet competencies similar to those established in Massachusetts for medical students, namely "recognize the risk factors for, and signs of, opioid overdose and demonstrate the correct use of naloxone rescue." 34,35 The most current substance use disorder curricular competencies for pharmacists do not include naloxone education as part of comprehensive harm reduction training and require updating. ${ }^{36,37}$ This is especially important since pharmacy students possess 
higher than average prevalence of risky substance use behaviors ${ }^{38}$ and are an essential component of overdose prevention and response. ${ }^{18,39}$ Surveys of practicing pharmacists have shown that despite successful programs on overdose education, ${ }^{40}$ pharmacists continue to lack confidence and willingness to prescribe and dispense naloxone..$^{41,42}$

One way to easily integrate training with an active learning component is to pair naloxone training with basic life support training a requirement of nearly all health professional schools. ${ }^{14,43}$ One study showed that while health professional training can be successful, a "cascade" approach to train other clinicians and then end-users of naloxone faces more barriers, further justifying required education of clinicians-in-training directly. ${ }^{44} \mathrm{~A}$ study of another public health training currently offered in pharmacy curricula nationwide, immunization training, did not demonstrate significant differences in confidence and knowledge based on student year in the program, indicating that training is feasible even early in the curriculum. ${ }^{45}$ The authors of this study also concluded that active learning should be integrated into immunization training, which informed our decision to include the active learning component of the OSCE in naloxone training.

\section{Limitations}

There are several limitations to this study, including potential differences in patient care experience between P1 and P2 students and the timing of survey administration. Some of the differences may have been due to P2 students simply having more experience and knowledge than P1 student. P2 students reported higher rates of employment in community pharmacy and would have more experience through Introductory Pharmacy Practice Experiences (IPPE), which are part of the required Doctor of Pharmacy curriculum. It is unknown however if P2 students would have had more exposure to opioid use disorders or overdose response topics in these settings however as employment and IPPE sites vary widely in the amount of patient contact provided and focus of the experience. Another limitation is that the survey for P2 students was sent via link in an email over summer break when students were not actively engaged in pharmacy courses. This contrasted with the P1 students who were given the opportunity to complete the survey while in class during the semester. While the study findings did not support our hypothesis that P2 students would have superior retention of knowledge related to opioid overdose and naloxone, we believe that the trend towards subjective response differences between the P1 and P2 students are important and illustrate both increased confidence with patient counseling and a reduced stigma for those who received an OSCE activity versus a lecture alone. Future studies should continue to enroll not only pharmacy students in studies of knowledge retention, confidence, and other subjective measure, but should include all health professional students.

\section{Conclusions}

We found that retention of the order of steps for naloxone administration when counseling patients on response to an overdose was increased among surveyed P2 students who received training from a didactic lecture plus an OSCE as compared to P1 student pharmacists who 
received a lecture only, however overall fact-based knowledge related to naloxone and opioids was similar. We have retained both teaching components in our curriculum based on the strength of OSCE as a tool for teaching addiction, ${ }^{46,47}$ the unremitting opioid epidemic in our state and region, and positive trends among surveyed P2 students related to an increased perception that overdose prevention with naloxone is not a waste of time or money.

\section{$\underline{\text { References }}$}

1. CDC WONDER. https://wonder.cdc.gov/. Accessed August 19, 2017.

2. Community Management of Opioid Overdose. Geneva: World Health Organization; 2014. http://www.ncbi.nlm.nih.gov/books/NBK264311/. Accessed August 18, 2017.

3. How can prescription drug misuse be prevented? | National Institute on Drug Abuse (NIDA). https://www.drugabuse.gov/publications/research-reports/misuse-prescriptiondrugs/how-can-prescription-drug-misuse-be-prevented. Accessed August 19, 2017.

4. Bohnert ASB, Valenstein M, Bair MJ, et al. Association between opioid prescribing patterns and opioid overdose-related deaths. JAMA. 2011;305(13):1315-1321.

doi:10.1001/jama.2011.370.

5. Jann M, Kennedy WK, Lopez G. Benzodiazepines: a major component in unintentional prescription drug overdoses with opioid analgesics. J Pharm Pract. 2014;27(1):5-16. doi:10.1177/0897190013515001.

6. Turner BJ, Liang Y. Drug Overdose in a Retrospective Cohort with Non-Cancer Pain Treated with Opioids, Antidepressants, and/or Sedative-Hypnotics: Interactions with Mental Health Disorders. J Gen Intern Med. 2015;30(8):1081-1096. doi:10.1007/s11606-0153199-4.

7. SAMHSA Opioid Overdose Prevention Tooklit. HHS Publication no. (SMA) 14-4742. 2014.

8. Yang Z, Wilsey B, Bohm M, et al. Defining risk of prescription opioid overdose: pharmacy shopping and overlapping prescriptions among long-term opioid users in medicaid. J Pain Off J Am Pain Soc. 2015;16(5):445-453. doi:10.1016/j.jpain.2015.01.475.

9. Edlund MJ, Martin BC, Russo JE, DeVries A, Braden JB, Sullivan MD. The role of opioid prescription in incident opioid abuse and dependence among individuals with chronic noncancer pain: the role of opioid prescription. Clin J Pain. 2014;30(7):557-564. doi:10.1097/AJP.0000000000000021.

10. Dunn KM, Saunders KW, Rutter CM, et al. Opioid prescriptions for chronic pain and overdose: a cohort study. Ann Intern Med. 2010;152(2):85-92. doi:10.7326/0003-4819152-2-201001190-00006.

11. Bird SM, McAuley A, Perry S, Hunter C. Effectiveness of Scotland's National Naloxone Programme for reducing opioid-related deaths: a before (2006-10) versus after (2011-13) comparison. Addict Abingdon Engl. 2016;111(5):883-891. doi:10.1111/add.13265. 
12. Strang J, McCambridge J, Best D, et al. Loss of tolerance and overdose mortality after inpatient opiate detoxification: follow up study. BMJ. 2003;326(7396):959-960. doi:10.1136/bmj.326.7396.959.

13. Green TC, Heimer R, Grau LE. Distinguishing signs of opioid overdose and indication for naloxone: an evaluation of six overdose training and naloxone distribution programs in the United States. Addict Abingdon Engl. 2008;103(6):979-989. doi:10.1111/j.13600443.2008.02182.x.

14. Lim JK, Bratberg JP, Davis CS, Green TC, Walley AY. Prescribe to Prevent: Overdose Prevention and Naloxone Rescue Kits for Prescribers and Pharmacists. J Addict Med. 2016;10(5):300-308. doi:10.1097/ADM.0000000000000223.

15. Kim HK, Nelson LS. Reducing the harm of opioid overdose with the safe use of naloxone: a pharmacologic review. Expert Opin Drug Saf. 2015;14(7):1137-1146. doi:10.1517/14740338.2015.1037274.

16. Combating opioid drug abuse with naloxone | American Pharmacists Association. https://www.pharmacist.com/combating-opioid-drug-abuse-naloxone. Accessed January 8, 2016.

17. Hagemeier NE, Alamian A, Murawski MM, Pack RP. Factors associated with provision of addiction treatment information by community pharmacists. J Subst Abuse Treat. 2015;52:67-72. doi:10.1016/j.jsat.2014.11.006.

18. Committee on Pain Management and Regulatory Strategies to Address Opioid Abuse, Board on Health Sciences Policy, Health and Medicine Division, National Academies of Sciences, Engineering, and Medicine. Pain Management and the Opioid Epidemic: Balancing Societal and Individual Benefits and Risks of Prescription Opioid Use. (Bonnie RJ, Ford MA, Phillips JK, eds.). Washington, D.C.: National Academies Press; 2017. doi:10.17226/24781.

19. Ray SM, Wylie DR, Shaun Rowe A, Heidel E, Franks AS. Pharmacy student knowledge retention after completing either a simulated or written patient case. Am J Pharm Educ. 2012;76(5):86. doi:10.5688/ajpe76586.

20. Baez A. Development of an Objective Structured Clinical Examination (OSCE) for Practicing Substance Abuse Intervention Competencies: An Application in Social Work Education. J Soc Work Pract Addict. 2005;5(3):3-20. doi:10.1300/J160v05n03_02.

21. Patil NG, Saing H, Wong J. Role of OSCE in evaluation of practical skills. Med Teach. 2003;25(3):271-272. doi:10.1080/0142159031000100319.

22. Administration of Naloxone in a Home or Community Setting: A Review of the Clinical Effectiveness, Cost-Effectiveness, and Guidelines. Ottawa (ON): Canadian Agency for Drugs and Technologies in Health; 2014. http://www.ncbi.nlm.nih.gov/books/NBK259232/. Accessed January 4, 2016.

23. Strang J, Manning V, Mayet S, et al. Overdose training and take-home naloxone for opiate users: prospective cohort study of impact on knowledge and attitudes and subsequent management of overdoses. Addict Abingdon Engl. 2008;103(10):1648-1657. 
doi:10.1111/j.1360-0443.2008.02314.x.

24. Geier M, Gasper JJ. Naloxone prescribing by psychiatric clinical pharmacists for patients receiving opioid agonist treatment. Ment Health Clin. 2015;5(1):46-49.

doi:10.9740/mhc.2015.01.046.

25. Behar E, Santos G-M, Wheeler E, Rowe C, Coffin PO. Brief overdose education is sufficient for naloxone distribution to opioid users. Drug Alcohol Depend. 2015;148:209212. doi:10.1016/j.drugalcdep.2014.12.009.

26. Hill KP, Rice LS, Connery HS, Weiss RD. Diagnosing and treating opioid dependence. J Fam Pract. 2012;61(10):588-597.

27. The First and Only Naloxone Auto-Injector EVZIO® (naloxone $\mathrm{HCl}$ injection). http://evzio.com/hcp/. Accessed January 8, 2016.

28. Walley AY, Doe-Simkins M, Quinn E, Pierce C, Xuan Z, Ozonoff A. Opioid overdose prevention with intranasal naloxone among people who take methadone. J Subst Abuse Treat. 2013;44(2):241-247. doi:10.1016/j.jsat.2012.07.004.

29. NARCAN®. http://narcannasalspray.com/. Accessed January 10, 2016.

30. Zayyan M. Objective Structured Clinical Examination: The Assessment of Choice. Oman Med J. July 2011:219-222. doi:10.5001/omj.2011.55.

31. SurveyMonkey: Free online survey software \& questionnaire tool. https://www.surveymonkey.com/. Accessed August 19, 2017.

32. Prescribe to Prevent: Overdose Prevention and Naloxone Rescue Kits for Prescribers and Pharmacists. http://www.opioidprescribing.com/naloxone_module_1-landing. Accessed August 19, 2017.

33. Rudd RA, Seth P, David F, Scholl L. Increases in Drug and Opioid-Involved Overdose Deaths - United States, 2010-2015. MMWR Morb Mortal Wkly Rep. 2016;65(5051):14451452. doi:10.15585/mmwr.mm655051e1.

34. Monteiro K, Dumenco L, Collins S, et al. An interprofessional education workshop to develop health professional student opioid misuse knowledge, attitudes, and skills. J Am Pharm Assoc JAPhA. 2017;57(2S):S113-S117. doi:10.1016/j.japh.2016.12.069.

35. Antman KH, Berman HA, Flotte TR, Flier J, Dimitri DM, Bharel M. Developing Core Competencies for the Prevention and Management of Prescription Drug Misuse: A Medical Education Collaboration in Massachusetts. Acad Med J Assoc Am Med Coll. 2016;91(10):1348-1351. doi:10.1097/ACM.0000000000001347.

36. Haack MR, Adger H. Executive summary: Strategic plan for interdisciplinary faculty development: Arming the nation's health professional workforce for a new approach to substance use disorders. Subst Abuse. 2002;23(sup1):1-21. doi:10.1080/08897070209511505.

37. Curricular Guidelines for Pharmacy - Substance Abuse and Addictive Disease.pdf. 
http://www.aacp.org/governance/SIGS/substanceabuse/Documents/Resources/Curricular \%20Guidelines\%20for\%20Pharmacy\%20-

\%20Substance\%20Abuse\%20and\%20Addictive\%20Disease.pdf. Accessed August 23, 2017.

38. Baldwin JN, Scott DM, DeSimone EM, Forrester JH, Fankhauser MP. Substance use attitudes and behaviors at three pharmacy colleges. Subst Abuse. 2011;32(1):27-35. doi:10.1080/08897077.2011.540470.

39. Green TC, Dauria EF, Bratberg J, Davis CS, Walley AY. Orienting patients to greater opioid safety: models of community pharmacy-based naloxone. Harm Reduct $\mathrm{J}$. 2015;12:25. doi:10.1186/s12954-015-0058-x.

40. Palmer E, Hart S, Freeman PR. Development and delivery of a pharmacist training program to increase naloxone access in Kentucky. J Am Pharm Assoc JAPhA. 2017;57(2S):S118-S122. doi:10.1016/j.japh.2016.12.071.

41. Nielsen S, Menon N, Larney S, Farrell M, Degenhardt L. Community pharmacist knowledge, attitudes and confidence regarding naloxone for overdose reversal. Addict Abingdon Engl. 2016;111(12):2177-2186. doi:10.1111/add.13517.

42. Thornton JD, Lyvers E, Scott VGG, Dwibedi N. Pharmacists' readiness to provide naloxone in community pharmacies in West Virginia. J Am Pharm Assoc JAPhA. 2017;57(2S):S12-S18.e4. doi:10.1016/j.japh.2016.12.070.

43. Berland N, Fox A, Tofighi B, Hanley K. Opioid overdose prevention training with naloxone, an adjunct to basic life support training for first-year medical students. Subst Abuse. 2017;38(2):123-128. doi:10.1080/08897077.2016.1275925.

44. Mayet S, Manning V, Williams A, Loaring J, Strang J. Impact of training for healthcare professionals on how to manage an opioid overdose with naloxone: effective, but dissemination is challenging. Int J Drug Policy. 2011;22(1):9-15. doi:10.1016/j.drugpo.2010.09.008.

45. Feret B, Orr K, Bratberg J, MacDonnell C. Evaluation of immunization training in the curriculum of first- and third-year pharmacy students. Curr Pharm Teach Learn. 2015;7(4):541-545. doi:10.1016/j.cptl.2015.04.013.

46. Parish SJ, Ramaswamy M, Stein MR, Kachur EK, Arnsten JH. Teaching about Substance Abuse with Objective Structured Clinical Exams. J Gen Intern Med. 2006;21(5):453-459. doi:10.1111/j.1525-1497.2006.00426.x.

47. Parish SJ, Stein MR, Hahn SR, Goldberg U, Arnsten JH. Teaching and assessing residents' skills in managing heroin addiction with objective structured clinical examinations (OSCEs). Subst Abuse. 2013;34(4):350-355. doi:10.1080/08897077.2013.776658. 